\title{
Model of Experimentation for Photoprotective Properties of Natural Products Against Ultraviolet C (UVC) Damage: A Case Study On Ros- marinic Acid
}

\author{
Camille Keisha Mahendra ${ }^{1}$, Loh Teng-Hern Tan ${ }^{1,2,3}$, Wei Hsum Yap ${ }^{4}$, Chim Kei Chan ${ }^{5}$, Prithvy Ling-
} ham $^{6}$, Priyia Pusparajah ${ }^{6}$, Thet Thet Htar ${ }^{1}$, Lay-Hong Chuah ${ }^{1,7}$, Bey Hing Goh ${ }^{1,8^{*}}$

\begin{abstract}
${ }^{1}$ Biofunctional Molecule Exploratory Research Group (BMEX), School of Pharmacy, Monash University Malaysia, 47500 Bandar Sunway, Selangor Darul Ehsan, Malaysia.

${ }^{2}$ Institute of Biomedical and Pharmaceutical Sciences, Guangdong University of Technology,

Guangzhou 510006, PR China.

${ }^{3}$ Novel Bacteria and Drug Discovery Research Group (NBDD), Microbiome and Bioresource Research Strength, Jeffrey Cheah School of Medicine and Health Sciences, Monash University, Bandar Sunway, Malaysia.

${ }^{4}$ School of Biosciences, Taylor's University, Subang Jaya, Selangor, Malaysia

${ }^{5}$ de Duve Institute, Avenue Hippocrate 74, 1200 Brussels, Belgium.

${ }^{6}$ Medical Health and Translational Research Group (MHTR), Jeffrey Cheah School of Medicine and Health Sciences, Monash University Malaysia, 47500 Bandar Sunway, Selangor Darul Ehsan, Malaysia.

${ }_{7}^{7}$ Advanced Engineering Platform, Monash University Malaysia, 47500 Bandar Sunway, Selangor Darul Ehsan, Malaysia. ${ }^{8}$ Institute of Pharmaceutical Science, University of Veterinary and Animal Science Lahore, Pakistan.
\end{abstract}

\begin{abstract}
UVC is one of the three forms of ultraviolet radiation that is produced by the sun and is harmful to those who are exposed to it. On earth, our ozone layer acts as a filter against UVC (solar UVC) from the sun. However, this is not the case for those exploring space as there would not be any filter for solar UVC once out of Earth's atmosphere. Additionally, although our ozone layer is able to filter solar UVC, non-solar UVC created by mankind can still pose a threat to those who utilize it for sterilization, research studies, medicine, etc. Identifying substances that could protect against this harmful form of radiation has significant potential; hence, we developed an experimental model to test a bioactive compound, romarinic aid (RA) in order to determine if it has photoprotective properties against UVC. To study the photoprotective properties of the compound, an experimental model using UVC lamp was set up and the cell viability of human keratinocyte cells treated with RA were measured with MTT and flow cytometry based apoptosis assays. The results obtained showed that RA was indeed able to attenuate the damaging effect of UVC, thus making it a potential candidate for further studies of photoprotection against solar and non-solar UVC. The model that was designed was shown to be reliable, reproducible and effective in screening UVC photoprotective properties in natural products. Thus, this opens up a new platform of natural product screening in the development of functional-cosmetics for astronauts and non-solar UVC users.
\end{abstract}

Keywords: Ultraviolet radiation (UVR); rosmarinic acid (RA); photoprotection; UVC; natural products

Received: $02^{\text {th }}$ May 2019

Accepted: $27^{\text {th }}$ June 2019

Published Online: $27^{\text {th }}$ July 2019

*Correspondence: Bey-Hing Goh, School of Pharmacy, Monash University Malaysia, 47500 Bandar Sunway, Selangor Darul Ehsan, Malaysia; goh.bey.hing@ monash.edu

Citation: Mahendra CK, Tan LTH, Yap WH, et al. Model of Experimentation for Photoprotective Properties of Natural Products Against Ultraviolet C (UVC) Damage: A Case Study On Rosmarinic Acid. Prog Drug Discov Biomed Sci 2019; 2(1): a0000027

\section{Introduction}

Ultraviolet rays (UVR) range from 200-400nm and consists of three types; UVA (320-400nm), UVB (290-320nm) and UVC (200-290nm $)^{[1]}$. UVB and UVC have been shown to be the most damaging as they are able to induce DNA damage directly ${ }^{[2,3]}$. Due to the oxygen in our atmosphere and our ozone layer, UVC or also known as solar UVC is unable to penetrate to the earth, however, this is not the case for astronauts traveling in space ${ }^{[4,5]}$ as there are no ozone layers to filter solar UVC. According to a study done by Schuster and his team ${ }^{[6]}$, the total radiation of solar UVC detected by EXPOSE-E, which was installed on the Columbus module outside the international space station (ISS), was recorded to be $18.28 \mathrm{MJ} /$ $\mathrm{m}^{2}$ when the devise was facing the sun. However, this figure only reflects for around $27 \%$ of the mission time due to the orbit of ISS which causes the devise to face away from the sun during the remainder mission time. Yet, these recorded solar UVC radiation are extremely high when compared to the conditions on earth, which is a concern for those working on the ISS as they are 
not only being exposed to ultraviolet rays but also galactic cosmic rays and solar proton events ${ }^{[6,7]}$. With the accumulation of radiation exposure, astronauts are at a higher risk of getting cancer and radiation poisoning ${ }^{[7,8]}$. Hence, the National Council of Radiation Protection and Measurements (NCRP) had limited a maximum increase of $3 \%$ in lifetime risk and $6 \times 10^{-4}$ annual risk of fatal cancer due to radiation exposure for those who are occupationally exposed to it. This is based on the assumption that one assumes a working life of 50 years and the lifetime risk is calculated based on age and dose limit of 10 $\mathrm{mSv}^{[9,10]}$. Besides that, there are still ongoing discussions on the possibility of humans relocating to Mars in the future, making it important to consider its atmospheric conditions as well. As Mars lacks significant ozone layer and has a lower atmospheric pressure as compared to earth, surface flux of ultraviolet radiation is much higher. Therefore, in depth studies on the necessary protection against UVB and solar UVC needs to be done ${ }^{[11]}$.

Other than solar UVC, there is also a different kind of UVC known as the non-solar UVC. This basically comes from UVC lamps that were made by men for either uses in factories, hospitals, research labs, etc. In factories, especially food factories, non-solar UVC has been basically used for germicidal purposes against microorganisms such as bacteria, fungi, viruses, algae, etc. This is so that the food that consumers consume are safe yet remain unchanged in colour, $\mathrm{pH}$ and flavor ${ }^{[2-14]}$. Studies on new waste water treatments also utilizes nonsolar UVC to degrade traces of antibiotics and harmful microorganisms found in waste waters ${ }^{[15,16]}$. Researchers are also using non-solar UVC for sterilization of equipment and multiple different experiments ${ }^{[17,18]}$. Besides that, there are studies done on the possibility of using UVC as an option to treat cancer patients either with the combination of photodynamic therapy (PDT) or fluorescence guided surgery (FGS ${ }^{[19-22]}$. With the possibility of non-solar UVC to be used as a medical treatment, the protection of patient against any adverse reactions to the treatment has to be taken into consideration as well. According to NCRP, the public can only be exposed to an increased fatal cancer lifetime risk of $0.4 \%$ and an annual risk of $5 \times 10^{-5}$, assuming one is exposed for a dose limit of $1 \mathrm{mSv}$ for 70 years $^{[10]}$. Therefore, further research on the effect of non-solar UVC has on the public should be studied further.

In light of the adverse effect of UVC overexposure on the human body, the need to develop UVC photoprotective product has to be considered. Natural products represent a great source of bioactive compounds. Rosmarinic acid (RA) is a bioactive natural product, which has been reported to exhibit photoprotective properties. RA, which is an ester of 3,4-dihyroxyphenyllactic acid and caffeic acid, is commonly found in plants from the Boraginaceae and sub-family of Nepetoideae from the Lamiaceae family ${ }^{[23]}$. Studies on RA had shown that it possess antioxidant, anti-cancer, anti-inflammation and anti-viral properties ${ }^{[24-26]}$. As for its photoprotective properties, RA had been reported by several studies to be able to attenuate cell damage caused by UVA and UVB by scavenging intracellular reactive oxygen species (ROS), increasing the activity of cellular antioxidant systems and decreasing apoptotic bodies, DNA strand breaks and inflammatory markers ${ }^{[27-29]}$. As RA had shown great aptitude in inhibiting the adverse effects of UVA and UVB, it was used as a sample in exploring UVC photoprotective effects experimental model setup. This is done to not only determine if RA has UVC photoprotective properties but also to evaluate the reliability of the UVC photoprotective model setup as shown in Figure 1.

\section{Photoprotection of Rosmarinic acid (RA) against UVC}

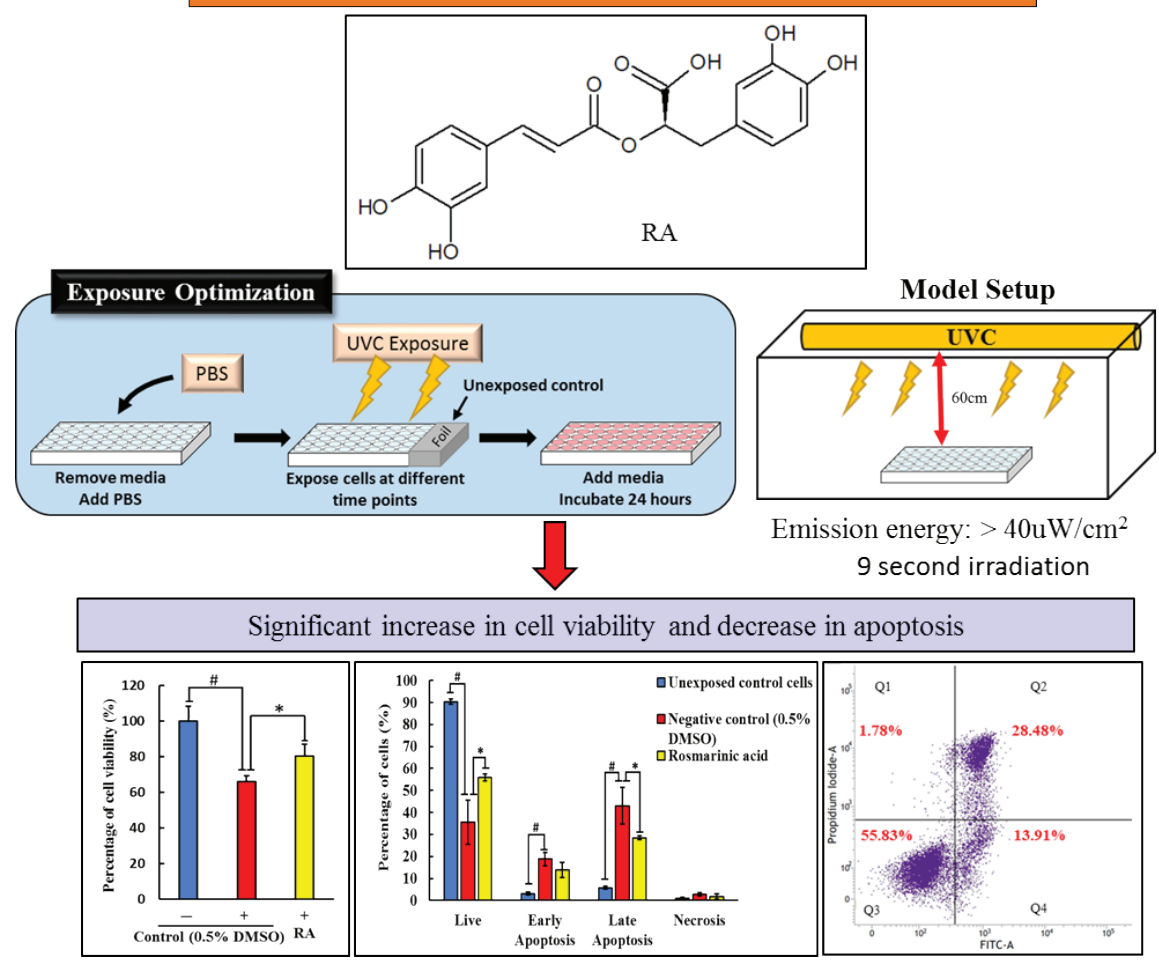

Figure 1. Overview of model setup to determine UVC photoprotective properties of RA. The optimal time of exposure for UVC was determined using MTT assay. The optimized model was employed to demonstrate the UVC photoprotective properties of RA. The effect of RA on the modulation of apoptosis induced by UVC was also analyzed using flow 


\section{Method details}

\section{Optimization of model setup for UVC exposure}

\section{Materials}

- Plasticware consumables: 96 well plates (NEST, USA), cell culture flasks (NEST, USA), $15 \mathrm{ml}$ Falcon tubes (NEST, USA), serological pipettes (Jet Biofil, China) and pipette tips (Axygen, USA).

- Tissue culture facilities equipped with inverted bright field microscope Olympus CKX41 (Olympus Japan), centrifuge (Eppendorf, Germany), microplate reader (BioTek, USA), biosafety cabinet (ESCO, Singapore) and $\mathrm{CO}_{2}$ incubator (Eppendorf, Germany).

- Camera and imaging software: ColorViewIII Soft Imaging System and AnalySIS ${ }^{\circledR}$ Software (Olympus, Japan)

- UVC lamp: ESCO germicidal UVC lamp (CRF/UV30A) (ESCO, Singapore)

- Human keratinocytes $(\mathrm{HaCaT})$ cell line

- Cell culture medium: 1x high-glucose Dulbecco Modified Eagle Medium (DMEM) GlutaMAX HEPES free (Gibco, USA) added with $1.0 \%$ of $100 x$ Antibiotic-antimycotic (Gibco, USA) and 10.0\% fetal bovine serum (FBS) (Gibco, USA).

- 1x Phosphate buffered saline (PBS) pH7.4 (Sigma, USA)

- 1x TrypLE Express (Gibco, USA)

- $\quad 0.4 \%$ Trypan blue stain

- Haemocytometer

- Aluminum sheet

- Stopwatch

\section{Procedure}

The optimization was implemented according to a previous protoco ${ }^{[30]}$ with slight modifications in which the cells were treated with a UVC lamp. After seeding the $\mathrm{HaCaT}$ cells at a density of $1 \times 10^{4}$ cells/well 24 hours prior to treatment, the cells were irradiated with ESCO germicidal UVC lamp which emits high intensity ultraviolet radiation with $95 \%$ of its emission intensity at peak emission of $253.7 \mathrm{~nm}$. The 96 well plate was placed at a distance of $60 \mathrm{~cm}$ from the UVC lamp and different samples were exposed to variable durations of irradiation namely 0,6 , 9 and 12 seconds. The emission energy emitted from the UVC lamp was more than $40 \mathrm{uW} / \mathrm{cm}^{2}$. The diagram of the experiment set up can be seen in Figure 2. After irradiation, the cells were incubated for 24 hours and cell viability was then analyzed with MTT assay.

The step by step breakdown of the process is as follows:

- Aspirate the media and add 50 $\mu 1$ of PBS into each well to form a thin layer of solution.
- Cover the unexposed control cells with aluminum sheets to block UVC irradiation.

- Irradiate the cells for 0, 6, 9 and 12 seconds.

- Add $150 \mu$ l of media into the wells and incubate for 24 hours before subjecting the cells to MTT assay.

(Note: The plastic cover of each plate was removed before irradiation and the outermost wells of each plate were not seeded with cells but added with water to prevent evaporation that may affect the MTT assay.)

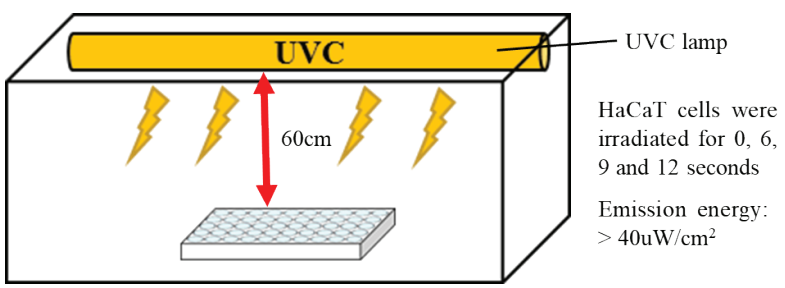

Figure 2. Parameters and model set up for the irradiation of $\mathrm{HaCaT}$ cells with UVC. HaCaT cells were irradiated for 0, 6, 9 and 12 seconds with ESCO germicidal UVC lamp at a distance of $60 \mathrm{~cm}$.

Concurrent Treatment of HaCaT cells with RA and UVC irradiation

Materials

- Plastic ware consumables: 96 well plates (NEST, USA), cell culture flasks (NEST, USA), $15 \mathrm{ml} \mathrm{Fal-}$ con tubes (NEST, USA), serological pipettes (Jet Biofil, China) and pipette tips (Axygen, USA).

- Tissue culture facilities equipped with inverted bright field microscope Olympus CKX41 (Olympus, Japan), centrifuge (Eppendorf, Germany), microplate reader (BioTek, USA), biosafety cabinet (ESCO, Singapore) and $\mathrm{CO}_{2}$ incubator (Eppendorf, Germany).

- Camera and imaging software: ColorViewIII Soft Imaging System and AnalySIS ${ }^{\circledR}$ Software (Olympus, Japan)

- UVC lamp: ESCO germicidal UV-C lamp (CRF/ UV-30A) (ESCO, Singapore)

- Human keratinocytes (HaCaT) cell line

- Cell culture medium: 1x high-glucose Dulbecco Modified Eagle Medium (DMEM) GlutaMAX HEPES free (Gibco, USA) added with $1.0 \%$ of 100x Antibiotic-antimycotic (Gibco, USA) and $10.0 \%$ fetal bovine serum (FBS) (Gibco, USA).

- 1x Phosphate buffered saline (PBS) pH7.4 (Sigma, USA)

- 1x TrypLE Express (Gibco, USA)

- $\quad 0.4 \%$ Trypan blue stain

- Haemocytometer

- Aluminum sheet

- Stopwatch

- RA prepared in $100 \%$ DMSO 


\section{Procedure}

In this step, RA will be used as a sample to validate the model setup as shown in Figure 1 and also to determine if it has UVC protective properties. In this step, the exposure time of 9 seconds was selected as the optimal time of exposure to induce significant cell death and sufficient live cells remained for analysis. Once again, $\mathrm{HaCaT}$ cells (1x $10^{4}$ cells/well) were seeded into a 96 well plate the day before and then exposed to UVC irradiation on the second day. The cells were then incubated again for 24 hours before MTT assay was used to analyze the percentage of cell viability and the all the data obtained were normalized against the viability of unexposed control cells.

- $\quad$ Prepare RA (40 $\mu \mathrm{g} / \mathrm{mL})$ in PBS with the presence of $0.5 \%(\mathrm{v} / \mathrm{v})$ DMSO. While for the unexposed control cells (cells that were neither treated nor irradiated) and negative control cells (irradiated cells that were not treated with RA), prepare PBS with the presence of $0.5 \%(\mathrm{v} / \mathrm{v})$ DMSO.

- Aspirate the media and pipette $50 \mu 1$ of mixed solution into each designated well.

- Cover the unexposed control cells with aluminum sheets.

- $\quad$ Irradiate the plate with UVC for 9 seconds.

- $\quad$ Aspirate the mixed solution and add in $150 \mu \mathrm{l}$ of media with $50 \mu \mathrm{l}$ of PBS to make up to a volume of $200 \mu 1$.

- Incubate the plate for 24 hours before proceeding with MTT assay the following day.

\section{$\underline{\text { MTT assay }}$}

Materials

- $\quad$ Dimethyl sulfoxide (DMSO)

- 3-(4,5-Dimethylthiazol-2-Y1)-2,5-Diphenyltetrazolium Bromide (MTT) reagent

Procedure

Cell viability was measured with 3-(4,5-Dimethylthiazol2-Y1)-2,5-Diphenyltetrazolium Bromide (MTT) assay as described by Goh and Kadir ${ }^{[31]}$, with slight modifications.

1. Pipette $20 \mu \mathrm{l}$ of MTT solution into each well.

2. Incubate for 2 hours to allow the formation of formazan crystal before removing the solution from each well.

3. Pipette in $100 \mu \mathrm{l}$ of DMSO per well to dissolve the formazan crystal

4. Measure the absorbance of each well with a microplate reader at $570 \mathrm{~nm}$

5. Calculate the cell viability for negative control and all samples by normalizing all data against unexposed control cells. Analyze the data with one-way analysis of variance (ANOVA) and Tukey HSD post-hoc tests using Statistical Package for Social Science (SPSS) version 24.0 with significant value set at $\mathrm{p}<0.05$ )
Apoptosis Assay of HaCaT treated with RA against $\underline{\mathrm{UVC}}$

Materials

- Plasticware consumables: 6 well plates (NEST, USA), cell culture flasks (NEST, USA), $15 \mathrm{ml}$ and $50 \mathrm{ml}$ Falcon tubes (NEST, USA), serological pipettes (Jet Biofil, China) and pipette tips (Axygen, USA).

- Tissue culture facilities equipped with inverted bright field microscope Olympus CKX41(Olympus, Japan), centrifuge (Eppendorf, Germany) biosafety cabinet (Esco, Singapore) and $\mathrm{CO}_{2}$ incubator (Eppendorf, Germany).

- UVC lamp: ESCO germicidal UV-C lamp (CRF/ UV-30A) (ESCO, Singapore)

- Human keratinocytes (HaCaT) cell line

- Cell culture medium: 1x high-glucose Dulbecco Modified Eagle Medium (DMEM) GlutaMAX HEPES free (Gibco, USA) added with $1.0 \%$ of 100x Antibiotic-antimycotic (Gibco, USA) and $10.0 \%$ fetal bovine serum (FBS) (Gibco, USA).

- $1 x$ Phosphate buffered saline (PBS) pH7.4 (Sigma, USA)

- 1x TrypLE Express (Gibco, USA)

- $\quad 0.4 \%$ Trypan blue stain

- Haemocytometer

- Aluminum sheet

- Stopwatch

- $\quad$ RA prepared in $100 \%$ DMSO

- Apoptosis assay: BD Annexin V FITC (Becton Dickinson, USA)

- Flow cytometer and its consumables: BD FACSVerse System, BD FACSuite Software, BD Falcon round-bottom tubes, BD FACSFlow sheath solution (Becton Dickinson, USA)

Procedure

This section is to investigate the inhibitory effect of RA on apoptosis of $\mathrm{HaCaT}$ cells induced by UVC. HaCaT cells $\left(3 \times 10^{5}\right.$ cells/well) were seeded into a 6 well plate the day before and then exposed to UVC irradiation on the second day. The cells were then incubated again for 24 hours before conducting the apoptosis assay. The apoptosis assay was performed to quantify the percentage of apoptotic cells.

Day 1:

1. Prepare RA $(40 \mu \mathrm{g} / \mathrm{mL})$ in PBS with the presence of $0.5 \%(\mathrm{v} / \mathrm{v})$ DMSO. While for the negative and unexposed control cells, prepare PBS with the presence of $0.5 \%(\mathrm{v} / \mathrm{v})$ DMSO.

2. Aspirate the media and rinse the wells with PBS to 
ensure complete removal of the media as the presence of media can affect the exposure of UVC.

3. Pipette $1.5 \mathrm{ml}$ of respective solution into each designated well seeded with $\mathrm{HaCaT}$ cells $\left(3 \times 10^{5}\right.$ cells/well).

4. Cover the unexposed control cells with aluminum sheets

5. Irradiate the plate with UVC for 9 seconds.

6. Aspirate the mixed solution and add in $2 \mathrm{ml}$ of media into each well

7. Incubate the plate for 24 hours.

Day 2:

1. Aspirate the media from each well and keep the solution in separate $15 \mathrm{ml}$ falcon tubes.

2. Rinse the cells with PBS and the "rinsed" PBS solution in its allocated falcon tube containing the aspirated media.

3. Add in $700 \mu \mathrm{l}$ of Tryple to each well and incubate the cells for 15 minutes.

4. Collect the cells from each well and aspirate them in its allocated falcon tube.

5. Rinse the wells with PBS and keep the "rinsed" PBS in its allocated falcon tube.

6. Centrifuge the cells at $1,500 \mathrm{rpm}$ for 5 minutes

7. Remove the supernatant from each falcon tube gently while retaining the pellet.

8. Add ice cold PBS into the falcon tube and resuspend the pellet.

9. Centrifuge the cells at $1,500 \mathrm{rpm}$ for 5 minutes

10. Remove the supernatant gently and add $1 \mathrm{ml}$ of ice cold $1 \mathrm{x}$ binding buffer to each falcon tube to resuspend the cells. (Dilute 10x binding buffer to $1 \mathrm{x}$ with sterile $\mathrm{H}_{2} \mathrm{O}$ )

11. Add $500 \mu \mathrm{l}$ of the resuspended cells to BD Falcon round bottom flask together with $2.5 \mu$ l of Annexin V and PI dye each in the dark.

12. Incubate the cells for 15 minutes in the dark on ice.

13. Read and analyze the percentage of apoptotic cells using BD FACSVerse System and BD FACSuite Software.

14. Analyze the data with one-way analysis of variance (ANOVA) and Tukey HSD post-hoc tests using Statistical Package for Social Science (SPSS) version 24.0 with significant value set at $\mathrm{p}<0.05$ )

(Note: Cells that are exposed to UVC may be harder to detach from its well. It is important to make sure that the almost all the cells are detached from the well before proceeding to rinse and stain the cells with the fluorescent dye. Besides that, the amount of fluorescent dyes should be accurately pipetted as it may also affect the flow cytometer reading)

\section{Methods Validation}

\section{Determination of optimal UVC exposure time}

HaCaT cells were irradiated for $0,6,9$ and 12 seconds at a distance of $60 \mathrm{~cm}$ from the UVC lamp. The time frame for each irradiation was controlled using a stopwatch and more than three independent experiments were conducted to verify the repeatability of the model. The effectiveness of UVC in inducing cell death in $\mathrm{HaCaT}$ cells are much stronger and quicker than when the cells were irradiated with $\mathrm{UVB}^{[30]}$. At just 6 seconds of exposure to UVC, the percentage of cell viability of $\mathrm{HaCaT}$ cells have already decreased significantly by $15.17 \% \pm$ $2.485(\mathrm{p} \leq 0.05)$. When increased in exposure time to 9 and 12 seconds, the cell viability continued to decrease by $35.20 \% \pm 3.169(\mathrm{p} \leq 0.05)$ and $58.79 \% \pm 1.823(\mathrm{p} \leq$ 0.05 ) respectively as can be seen in Figure 3 . The microscopic images that were portrayed in Figure 4 supports the data obtained. After much evaluation, exposure time of 9 seconds was chosen to be the optimal time of exposure.

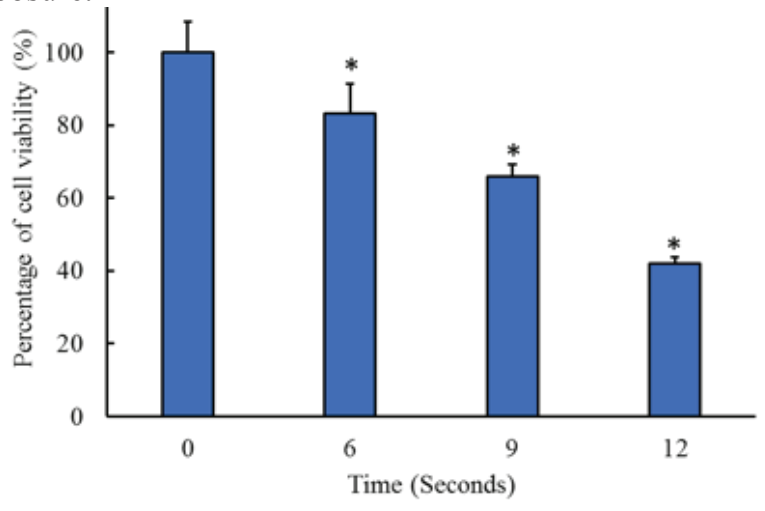

Figure 3. Determination of optimal time of UVC exposure for HaCaT cells. $\mathrm{HaCaT}$ cells $\left(1 \times 10^{4}\right.$ cells/well), covered in a thin layer of PBS, were irradiated for $0,6,9$ and 12 seconds. Cell viability was then measured after 24 hour incubation using MTT assay. Cells that were not exposed to UVC ( 0 seconds - unexposed control cells) were assumed to be at $100 \%$ viability and the viability of the exposed cells were normalized against the unexposed control cells. All data were expressed as mean \pm standard error $(n=6)$.with the significant value set at $* \mathrm{p} \leq 0.05$.

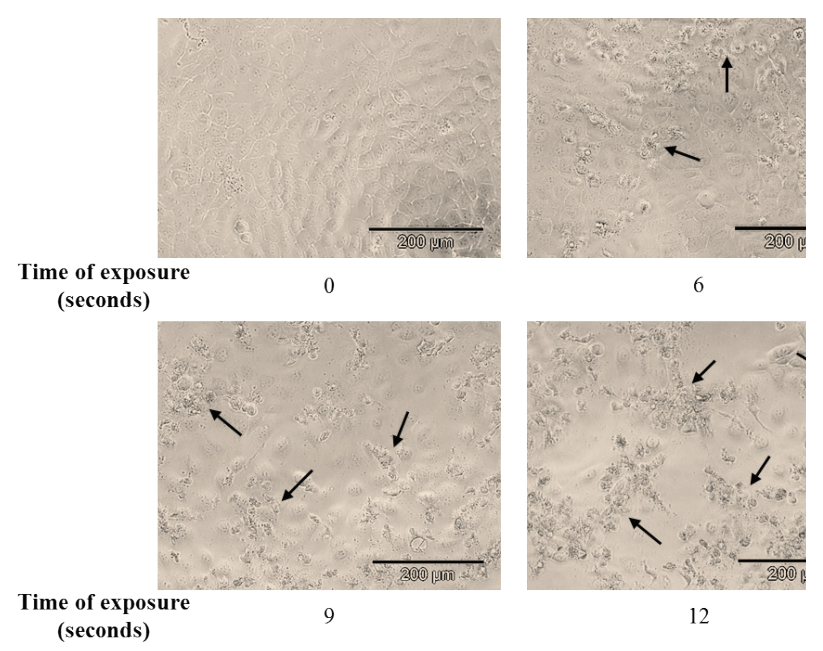

Figure 4. Microscopic images (10x magnification) of HaCaT cells 24 hours after being exposed to UVC at different time points ( 0 , 6, 9 and 12 seconds). The arrows indicate UVC-induced cell death. 


\section{Photo protective properties of RA against UVC}

RA was analyzed for UVC photoprotective properties as it was previously reported in other studies to have UVA and UVB protective properties ${ }^{[28,29]}$. Based on the results depicted in Figure 5, RA was able to significantly attenuate the photo-damage caused by UVC irradiation. With the application of RA to $\mathrm{HaCaT}$ cells in concurrent with UVC irradiation, the viability of the cells were significantly increase up to $78.84 \% \pm 6.487$ as compared to the negative control which has a cell viability of $64.80 \% \pm 3.169$. This shows that RA is able to protect the HaCaT cells from UVC irradiation.

(A)
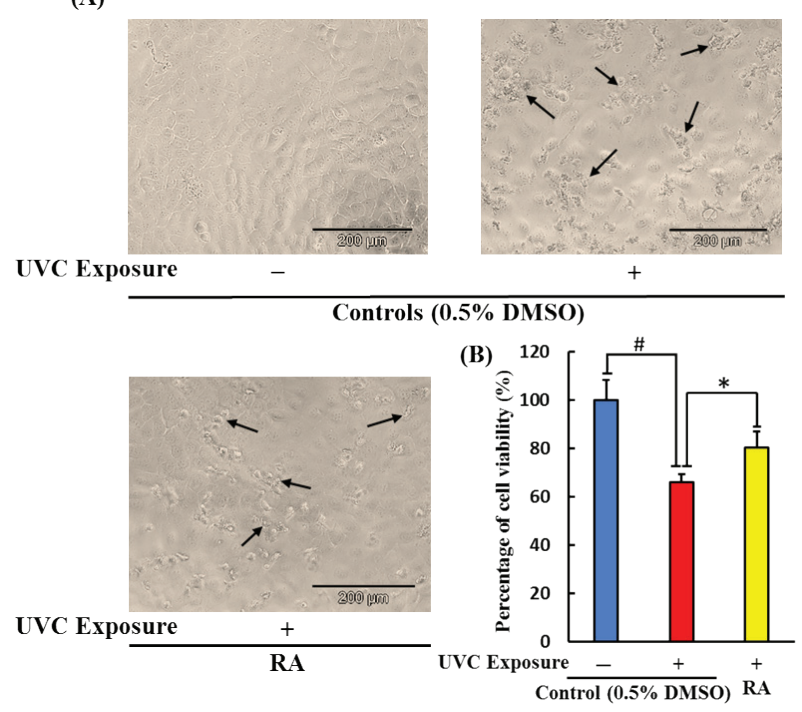

Figure 5. Protective properties of RA against UVC irradiation. HaCaT cells that were treated with RA ( $40 \mu \mathrm{g} / \mathrm{ml})$ were compared against the negative control while the negative control cells were compared against the unexposed control cells to determine significant value.

\section{Flow Cytometric Analysis of Apoptosis in Cells Treated with RA}

To verify the results obtained through MTT assay, the percentage of apoptotic cells was analyzed for the cells that were treated with RA. As can be seen in Figure 7, the percentage of live cells significantly decreased when the cells were exposed to UVC. The unexposed control cells had $90.37 \%$ of cells that were still alive while the negative control cells only had $35.54 \%$ live cells. When it comes to the cells in early and late apoptotic stages, significant increase in the percentage of cells can be seen in the negative control as compared to the unexposed cells. An increase of $3.11 \%$ to $18.73 \%$ can be seen for early apoptotic cells, while late apoptotic cells had increased from $5.75 \%$ to $43.01 \%$. There are no significant difference between the negative control and the unexposed cells when it comes to the percentage of necrotic cells although there are more cells in the necrosis phase for negative control cells as compared to the unexposed control cells.

On the other hand, cells that were treated with RA, had shown a significant improvement on the percentage of cells that were alive when compared between the negative control cells. The percentage of live cells had increased from $35.54 \%$ to $55.83 \%$ when treated with RA concurrent with UVC exposure. There was also a decrease in early and late apoptosis for RA-treated cells, although only the percentage of late apoptotic cells shown significant decrease when compared to the negative control. However, even though there was no significant difference in the percentage of cells for early apoptosis, the percentage did decrease from $18.73 \%$ to $13.91 \%$. For the late apoptotic cells, the percentage obtained displayed a significant drop from $43.01 \%$ to $28.48 \%$. Finally, for the necrotic cells, there were no significant difference between the negative control cells $(2.72 \%)$ and cells treated with RA (1.78\%).

Based on the results obtained, it is suggested that RA is able to attenuate the damaging effects of UVC, especially in reducing the percentage of cells in late apoptotic phase and increasing the percentage of live cells. Therefore, further studies should be done on RA as it could potentially help in developing UVC photoprotective products for both astronauts and non-solar UVC users. On the other hand, the experiments done also tests the reliability of this model in screening for UVC photoprotective properties in natural products. Despite the wavelength of the UVC lamp used have $95 \%$ of its emission intensity $253.7 \mathrm{~nm}$ and may not be completely similar to those emitted by the sun, it is similar to those used to study the effectiveness of UVC in the treatment of cancer ${ }^{[19,20,32]}$. From the results obtained, this model setup had showed its reliability and ability to produce reproducible results in the screening of UVC photoprotective properties in natural products. Thus, allowing for more rapid screens of natural products.

\section{Summary}

In short, RA was able to reduce the photo-damage of UVC on human keratinocyte cells through cell viability measurements via MTT and apoptosis assays. Hence, RA shows much potential as a photoprotective bioactive compound that can be developed further for its application in space or for non-solar UVC users. In the future, further research can also be done on RA to determine if it can not only block UVB and UVC but also other radiations that can be found in space and on Mars. On the other hand, the model that was designed had shown to be reliable, effective and reproducible in screening for UVC photoprotective properties in natural products. With this, many different natural products can be screen for photoprotection against UVC, thus not only aiding in the furtherance of space science but also aid in the development of cost effective functional cosmetic products for those who are exposed to non-solar UVC.

\section{Acknowledgements}

This research was financially supported by External Industry Grant (Biotek Abadi - Vote No. GBA-81811A) \& Taylor's University Emerging Grant (TRGS/ ERFS/2/2018/SBS/016).

\section{Conflict of Interest}

The authors declared that there is no conflict of interest. 

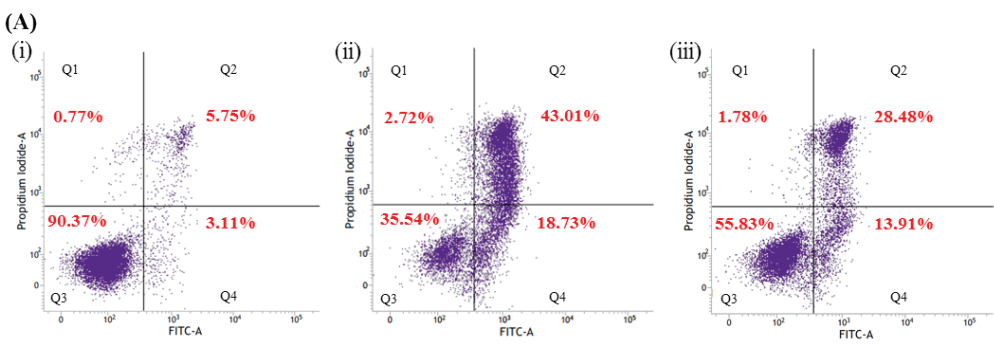

(B)

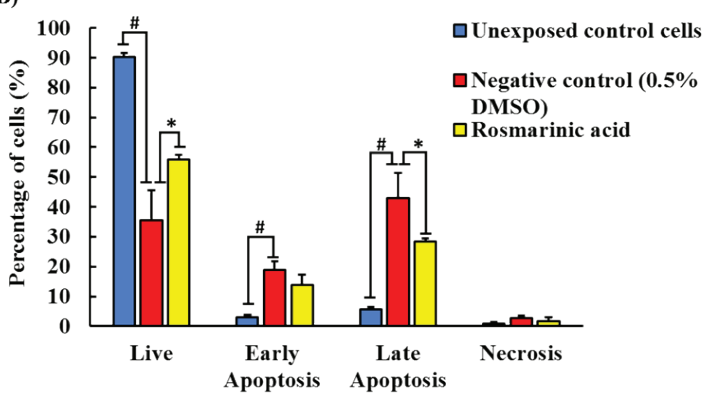

Figure 7. Measurement of the photoprotective properties of RA against UVC irradiation using flow cytometric analysis. HaCaT cells (3x105 cells/well) was exposed to UVC for 9 seconds and then incubated for 24 hours before measuring it's the percentage of apoptotic cells. (A) Changes in percentage of apoptotic cells after being treated by RA shown through scatter plot of propidium iodide vs FITC Annexin V. Q1: Necrosis; Q2: Late apoptosis; Q3: Live; Q4: Early apoptosis (i) Unexposed control cells. (ii) Negative control cells (iii) Cells treated with 40 $\mathrm{g} / \mathrm{ml} \mathrm{RA}$ and irradiated with UVC. (B) Bar chart comparing the difference in percentage of cells present in each quadrant (Q1, 2, 3 and 4) between the different treatments. All data were expressed as mean \pm standard error where $\mathrm{n}>3$ (Negative control: \# $\mathrm{p} \leq 0.05)($ Treatment with RA: * $\mathrm{p} \leq 0.05)($ “ + ” symbol $=$ exposed cells; “-” symbol = unexposed cells).

\section{Reference}

1. Widel M, Krzywon A, Gajda K, et al., Induction of bystander effects by UVA, UVB, and UVC radiation in human fibroblasts and the implication of reactive oxygen species. Free Radic Biol Med, 2014. 68: 278287.

2. Huselton CA, Hill HZ, and O'Neill JP, Melanin photosensitizes ultraviolet light (UVC) DNA damage in pigmented cells. Environ Mol Mutagen, 1990. 16(1): 37-43

3. You YH, Lee DH, Yoon JH, et al., Cyclobutane pyrimidine dimers are responsible for the vast majority of mutations induced by UVB irradiation in mammalian cells. J Biol Chem, 2001. 276(48): 44688-44694

4. Rivas M and Rojas E, Effects of ozone layer variation in Ultraviole solar radiation level received at ground in Arica north of Chile. Journa of Physics: Conference Series, 2018. 1043: 012066.

5. Abbasi SA and Abbasi T, Impacts of ozone hole, In: Ozone hole: past, present, future. New York: Springer, 2017. 51-99.

6. Schuster M, Dachev T, Richter P, et al., R3DE: radiation risk radiometer-dosimeter on the international space station - optical radiation dat recorded during 18 months of expose-e exposure to open space. Astrobiology, 2012. 12(5): 393-402

7. Kim MHY, George KA, and Cucinotta FA, Evaluation of skin cance risk for lunar and Mars missions. Adv Space Res, 2006. 37(9): 1798 1803.

8. Hines JW, Townsend LW, and Nichols TF, SPE dose prediction using locally weighted regression. Radiat Prot Dosimetry, 2005. 116(1-4): 131-134

9. Cucinotta FA, Space radiation risks for astronauts on multiple international space station missions. PLoS One, 2014. 9(4): e96099.

10. Kase KR, Radiation protection principles of NCRP. Health Physics, 2004. 87(3): 251-257.

11. Cockell CS, Catling DC, Davis WL, et al., The ultraviolet environment of Mars: biological implications past, present, and future. Icarus, 2000. 146(2): 343-359.

12. Valero A, Begum M, Leong SL, et al., Effect of germicidal UVC ligh on fungi isolated from grapes and raisins. Lett Appl Microbiol, 2007. 45(3): 238-243.

13. Begum M, Hocking AD, and Miskelly D, Inactivation of food spoilage fungi by ultra violet (UVC) irradiation. Int J Food Microbiol, 2009. 129(1): 74-77.

14. Flores-Cervantes DX, Palou E, and López-Malo A, Efficacy of individual and combined UVC light and food antimicrobial treatments to inactivate Aspergillus flavus or A. niger spores in peach nectar. Innov Food Sci Emerg Technol, 2013. 20: 244-252.

15. Velo-Gala I, Pirán-Montaño, JA, Rivera-Utrilla J, et al., Advanced oxidation processes based on the use of UVC and simulated solar radiation to remove the antibiotic tinidazole from water. Chem Eng J, 2017. 323 605-617.

16. Giannakis S, Androulaki B, Comninellis C, et al., Wastewater and urine treatment by UVC-based advanced oxidation processes: Implications from the interactions of bacteria, viruses, and chemical contaminants. Chem Eng J, 2018. 343: 270-282.

17. Shie JL, Lee CH, Chiou CS, et al., Photodegradation kinetics of formal- dehyde using light sources of UVA, UVC and UVLED in the presence of composed silver titanium oxide photocatalyst. J Hazard Mater, 2008. 155(1): 164-172.

18. Narita K, Krisana A, Morimoto Y, et al., Disinfection and healing effects of 222-nm UVC light on methicillin-resistant Staphylococcus aureus infection in mouse wounds. J Photochem Photobiol B, 2018. $178: 10-18$

19. Hiroshima Y Maawy A, Zhang Y, et al., Fluorescence-guided surgery in combination with UVC irradiation cures metastatic human pancreatic cancer in orthotopic mouse Models. PLoS One, 2014. 9(6): e99977.

20. Momiyama M, Atsushi S, Kimura H, et al., Imaging the efficacy of UVC irradiation on superficial brain tumors and metastasis in live mice at the subcellular level. J Cell Biochem, 2013. 114(2): 428434.

21. Zacal N and Rainbow AJ, Photodynamic therapy resistant human colon carcinoma HT29 cells show cross-resistance to UVA but no UVC light. Photochem Photobiol, 2007. 83(3): 730-737.

22. Momiyama M, Atsushi S, Kimura $\mathrm{H}$, et al., Fluorescent protein enhance UVC PDT of cancer cells. Anticancer Res, 2012. 32(10): 4327-4330.

23. Petersen M and Simmonds MSJ, Rosmarinic acid. Phytochemistry, 2003. 62(2): p. 121-125

24. Moon DO, Kim MO, Lee JD, et al., Rosmarinic acid sensitizes cell death through suppression of TNF- $\alpha$-induced NF- $\mathrm{\kappa B}$ activation and ROS generation in human leukemia U937 cells. Cancer Lett, 2010. 288(2): 183-191.

25. Swarup V, Joydeep G, Sourmya G, et al., Antiviral and anti-inflammatory effects of rosmarinic acid in an experimental murine model of japanese encephalitis. Antimicrob Agents and Chemother, 2007. 51(9): 3367.

26. Osakabe N, Takano H, Sanbongi C, et al., Anti-inflammatory and anti-allergic effect of rosmarinic acid (RA); inhibition of seasonal allergic rhinoconjunctivitis (SAR) and its mechanism. BioFactors, 2004. 21(1-4): 127-131

27. Fernando PMDJ, Piao MJ, Kang KA, et al., Rosmarinic acid attenuates cell damage against UVB radiation-induced oxidative stress via enhancing antioxidant effects in human $\mathrm{HaCaT}$ cells. Biomol Ther, 2016. 24(1): 75-84.

28. Psotova J, Svobodova A, Kolarova H, et al., Photoprotective properties of Prunella vulgaris and rosmarinic acid on human keratinocytes. J Photochem Photobiol B, 2006. 84(3): 167-174.

29. Vostálová J, Zdařilová A, and Svobodová A, Prunella vulgaris extract and rosmarinic acid prevent UVB-induced DNA damage and oxidative stress in HaCaT keratinocytes. Arch Dermatol Res, 2010 302(3): 171-181.

30. Mahendra CK, Tan LTH, Yap WH, et al., An optimized cosmetic screening assay for ultraviolet B (UVB) protective property of natural products. Progress in Drug Discovery \& Biomedical Science, 2019. 2(1): 1-6.

31. Goh BH, and Kadir AH, In vitro cytotoxic potential of Swietenia macrophylla King seeds against human carcinoma cell lines. J Med Plant Res, 2011. 5(8): 1395-1404.

32. Kimura H, Lee C, Hayashi K, et al., UV light killing efficacy of fluorescent protein-expressing cancer cells in vitro and in vivo. Cell Biochem, 2010. 110(6): 1439-1446. 